\title{
Factors associated with C-reactive protein testing when prescribing antibiotics in general practice: a register-based study
}

Rikke Vognbjerg Sydenham ${ }^{1 *}$, Malene Plejdrup Hansen², Ulrik Stenz Justesen³ , Line Bjørnskov Pedersen ${ }^{1,4}$, Rune Munck Aabenhus ${ }^{5}$, Sonja Wehberg ${ }^{1}$ and Dorte Ejg Jarbøl ${ }^{1}$

\begin{abstract}
Background: The use of C-reactive protein (CRP) tests has been shown to safely reduce antibiotic prescribing for acute respiratory tract infections (RTIs). The aim of this study was to explore patient and clinical factors associated with the use of CRP testing when prescribing antibiotics recommended for RTIs.

Methods: A nation-wide retrospective cross-sectional register-based study based on first redeemed antibiotic prescriptions issued to adults in Danish general practice between July 2015 and June 2017. Only antibiotics recommended for treatment of RTIs were included in the analysis (penicillin-V, amoxicillin, co-amoxicillin or roxithromycin/ clarithromycin). Logistic regression models were used to estimate odds ratios for patient-related and clinical factors on performing a CRP test in relation to antibiotic prescribing.

Results: A total of 984,149 patients redeemed at least one antibiotic prescription during the two-year period. About half of these prescriptions (49.6\%) had an RTI stated as the indication, and a CRP test was performed in relation to $45.2 \%$ of these scripts.

Lower odds of having a CRP test performed in relation to an antibiotic prescription was found for patients aged 75 years and above (OR 0.82, 95Cl 0.79-0.86), with a Charlson Comorbidity Index of more than one (OR 0.93,95Cl 0.91-0.95), unemployed or on disability pension (OR 0.84, 95Cl 0.83-0.85) and immigrants (OR 0.91, 95Cl 0.88-0.95) or descendants of immigrants (OR 0.90,95Cl 0.84-0.96). Living with a partner (OR 1.08,95Cl 1.07-1.10), being followed in practice for a chronic condition (OR 1.22, 95CI 1.18-1.26) and having CRP tests performed in the previous year (OR $1.78,95 \mathrm{Cl} 1.73-1.84)$ were associated with higher odds of CRP testing in relation to antibiotic prescribing.

Conclusions: Differences were observed in the use of CRP tests among subgroups of patients indicating that both sociodemographic factors and comorbidity influence the decision to use a CRP test in relation to antibiotic prescriptions in general practice. Potentially, this means that the use of CRP tests could be optimised to increase diagnostic certainty and further promote rational prescribing of antibiotics. The rationale behind the observed differences could be further explored in future qualitative studies.
\end{abstract}

Keywords: General practice, Anti-bacterial agents, Drug prescriptions, Diagnostic test, C-reactive protein

*Correspondence: rsydenham@health.sdu.dk

1 Research Unit of General Practice, Institute of Public Health, University of Southern Denmark, JB Winsløws Vej 9A, 5000 Odense C, Denmark

Full list of author information is available at the end of the article

\section{Background}

Most acute respiratory tract infections (RTIs) are either non-severe or of viral origin [1-3]. Still, these infections are frequently treated with antibiotics although it will often only add marginal benefits $[2,4,5]$. 
Refraining from using antibiotics in the mildly to moderately ill patients, where modest benefit can be expected, can minimise the risk of side effects for these patients and in a societal perspective reduce antibiotic resistance and costs [6-8]. This approach will preserve the effectiveness of antibiotics and ensure relevant treatment of serious infections in the severely ill.

Current Danish national guidelines recommend penicillin-V as first-line treatment for RTIs, except for exacerbation of chronic obstructive pulmonary disease (COPD) for which amoxicillin is now recommended. Up until 2017 amoxicillin with clavulanic acid (co-amoxicillin) was recommended for treatment of COPD patients. For patients with penicillin allergy, either clarithromycin or roxithromycin is recommended [9]. In Denmark, azithromycin is not recommended as first line treatment of RTIs in general practice.

General practitioners (GPs) are influenced by many factors when managing patients with signs and symptoms of an infection, and the $\mathrm{C}$-reactive protein (CRP) test can be a useful diagnostic tool when determining if an antibiotic treatment is likely to prove beneficial or should be withheld [10-14].

The vast majority of general practices in Denmark performs CRP tests as point-of-care analysis. Furthermore, all practices can send samples for analysis at the hospital laboratory. Consultations and diagnostic tests are free of charge to the patient and reimbursed from the health authorities [15]. A recent Danish study showed that when GPs are provided with the result of a CRP test it constitutes an important part of the decision to prescribe or withhold antibiotics [16]. Another Danish study found that CRP tests were performed in relation to about $20 \%$ of all antibiotic prescriptions issued in general practice, and differences in the use of CRP tests was observed between different antibiotic types [17].

Focussing solely on RTIs, studies have shown that CRP testing can safely reduce the use of antibiotics [18-22]. Consensus exists that CRP testing cannot stand alone but should be interpreted alongside medical history, clinical findings and assessment of risk for the individual patient [23]. The Danish College of General Practitioners encourages the use of CRP as a diagnostic tool when reasonable clinical uncertainty exists. Howeverit is unknown which factors influence GPs to perform a CRP test and whether differences are present in the use among various patient characteristics. The aim of this study was to explore patient and clinical factors associated with the use of CRP testing when prescribing antibiotics recommended for treatment of RTIs. The study can potentially identify areas where the use of CRP tests could be optimised to increase diagnostic certainty and further promote rational prescribing of antibiotics.

\section{Methods}

This nationwide study is a retrospective cross-sectional register-based study linking Danish national registers for the adult population. Data were linked at patient-level using encrypted civil registration numbers.

\section{Setting}

Health services in Denmark are tax-funded and medical expenditures partly subsidised. About $98 \%$ of all Danish citizens are registered with a GP. GPs are remunerated through a mixed capitation and fee-for-service system with fees for a consultation and additional fees for performing different services including CRP tests. The outof-hour services (OOHS) are organised by the GPs in four of the five Danish Regions [15]. In the fifth region the OOHS is organised by the Regional health care service.

\section{Study population, data sources and variables for the study} The Danish National Prescription Registry was used to define the population. This database contains complete information on all prescriptions redeemed by Danish residents at outpatient pharmacies in Denmark from January 1st, 1995 and onwards. The study population comprised all Danish patients aged 18 years and above redeeming prescriptions for one of the following antibiotics: penicillin-V (Anatomical Therapeutic Chemical Classification code (ATC) J01CE02), amoxicillin (ATC J01CA04), co-amoxicillin (ATC J01CR02) or roxithromycin/clarithromycin (ATC J01FA06 and J01FA09) in the project period from July 2015 to June 2017 . These antibiotics were selected since they are the recommended as first line treatment for RTIs in Denmark [9]. The two-year timespan was used to take season variation into account, to avoid distortion of data due to e.g. an influenza epidemic and to allow inclusion of patients without frequent antibiotic use. Solely prescriptions issued from general practice or OOHS were included in this study. If a patient had redeemed several antibiotic prescriptions during the project period, only information about the first prescription was used for the analyses. A 14-days antibiotic freeperiod, covering all types of antibiotics, was required for inclusion in the study. All information was linked using encrypted unique person identification numbers.

In order to define the diagnosis for which each prescription was issued, indication codes were used. We categorised the prescriptions according to indication codes stated on the prescription by the prescriber. A full list of indication codes is available in Additional file 1: List of indication codes and categorisation for prescriptions.

Univariable and multivariable analyses were performed for Model 1) all prescriptions of antibiotics recommended as first line treatment of RTIs and Model 2) 
the subgroup of these prescriptions with an RTI stated as the specific indication.

The primary outcome measure for the study was the binary variable: whether or not a CRP test was performed in general practice in relation to antibiotic prescriptions. Information about the performance of CRP testing was retrieved from the Danish National Health Service Register. Since GPs report their services, including CRP tests, to the Danish National Health Service Register at a weekly basis, we defined the date of the CRP test as the Wednesday in the week of reporting. Therefore, a timespan of up to seven days between the performance of a CRP test and redemption of prescription was allowed when defining the two measures as related.

GP reimbursement reports obtained from the Danish National Health Service Register were used to compute the number of CRP tests performed and number of consultations in the year before the antibiotic prescription was issued, and whether the patient had followup consultations for one or more chronic conditions the previous year. We counted tests and consultations from 14 days before the prescription and one year back to avoid including CRP tests/consultations related to the current event. Season of prescription was defined in two groups: October-March and April-September. The number of antibiotic prescriptions in the previous 365 days before date of first prescription was counted for each patient.

The Danish National Patient Register was used to quantify the burden of disease classifying comorbid conditions at the patient level by computing Charlson Comorbidity Indexusing the Quan 2011 method without age adjustment. Healthcare contacts in a 10-year period prior to prescription were used for computing Charlson Comorbidity Index [24].

Socioeconomic information at the patient level were retrieved from Statistics Denmark and linked to the prescription by encrypted unique person identification numbers. Socioeconomic variables included information on gender, age groups (18-44, 45-64, 65-74, and + 75 years), length of education (<10years, $10-15$ years, $>15$ years), labour market affiliation (working, pension, out of workforce/disability pension), cohabitation status (single, married/partner), and ethnicity (Danish, immigrant, descendent of immigrants). For patients with missing information in the year of prescription, we used information from the previous year, alternatively the following year. If neither were available, the patient was assigned to the largest group.

From the Service Provider Register we retrieved speciality codes to identify GPs. We used this information to take clustering at practice level into account.

\section{Statistical analysis}

Using descriptive statistics, we generated information on characteristics related to the redeemed antibiotic prescriptions in terms of patient characteristics and clinical characteristics as defined above. We used logistic regression models to estimate odds ratios (OR) with 95\% confidence intervals (95CI) for associations between the patient-related and clinical factors and the use of CRP test in relation to prescription of antibiotics for RTIs. Univariable and multivariable analyses were performed for Model 1) all prescriptions of antibiotics recommended as first line treatment of RTIs and Model 2) the subgroup of these prescriptions with an RTI stated as the specific indication. The rationale behind presenting both models is that we wanted to examine use of CRP tests related to RTIs. However, the completeness of the diagnoses stated on the prescriptions was not sufficient to use on its own. To illustrate potential differences when restricting to antibiotics prescriptions with RTI stated as the indication Model 2 was included.

As sensitivity analysis, we also estimated a model including prescriptions with any indications that could possibly contain an RTI, i.e. we included the indications 'against infection' and missing indication. Clustering at practice level was taken into account.

All statistical analyses were performed using Stata 16 [25].

\section{Results}

\section{Characteristics of patients redeeming an antibiotic} prescription

Table 1 provides a descriptive overview of the population. A total of 984,149 individuals redeemed a first-time prescription of one of the four selected antibiotic types. An RTI was stated as the indication on about half of the prescriptions (49.6\%). Some $12.9 \%$ of the scripts did not include an indication and another $17.4 \%$ did not specify for which type of infection the antibiotic was issued, and the remaining prescriptions had a specific indication.

\section{Factors associated with the use of CRP}

Table 2 presents two multivariable models. Model 1 included all prescriptions of the fourmost commonly recommended antibiotics for treatment of RTIs. A CRP test was performed in relation to $34.1 \%$ of these prescriptions. Model 2 was restricted to the subgroup of prescriptions where RTI was stated as the indication. For these a CRP test was conducted in $45.2 \%$ of prescribing cases.

The multivariable model including all prescriptions within the four types of antibiotics (model 1) showed that females had slightly higher odds of having a CRP test performed in relation to antibiotic prescribing 
Table 1 Characteristics of patients redeeming antibiotic prescriptions overall and for the subgroup of prescriptions where the GP stated RTI as indication

\begin{tabular}{|c|c|c|}
\hline & $\begin{array}{l}\text { The four types of antibiotics } \\
\text { recommended for RTls }\end{array}$ & $\begin{array}{l}\text { The four types of antibiotics } \\
\text { recommended for RTIs with RTI as } \\
\text { stated indication }\end{array}$ \\
\hline & $(n=984.149)$ & $(n=487,939)$ \\
\hline \multicolumn{3}{|l|}{ Patient characteristics } \\
\hline \multicolumn{3}{|l|}{ Gender } \\
\hline Male & $427,735(43.5)$ & $203,123(41.6)$ \\
\hline Female & $556,414(56.5)$ & $284,816(58.4)$ \\
\hline \multicolumn{3}{|l|}{ Age } \\
\hline $18-44$ & $377,404(38.3)$ & $204,543(41.9)$ \\
\hline $45-64$ & $314,242(31.9)$ & $145,060(29.7)$ \\
\hline $65-74$ & $157,136(16.0)$ & $73,018(15.0)$ \\
\hline $75+$ & $135,367(13.8)$ & $65,318(13.4)$ \\
\hline \multicolumn{3}{|l|}{ Education } \\
\hline$<10$ years & $205,261(20.9)$ & $102,338(21.0)$ \\
\hline 10-15years & $569,126(57.8)$ & $281,636(57.7)$ \\
\hline$>15$ years & $209,762(21.3)$ & $103,965(21.3)$ \\
\hline \multicolumn{3}{|l|}{ Labour market affiliation } \\
\hline Working & $535,219(54.4)$ & $275,368(56.4)$ \\
\hline Pension & $290,588(29.5)$ & $138,098(28.3)$ \\
\hline Out of workforce, Disability pension & $158,342(16.1)$ & $74,473(15.3)$ \\
\hline \multicolumn{3}{|l|}{ Cohabitation status } \\
\hline Single & $505,003(51.3)$ & $252,247(51.7)$ \\
\hline Married/Partner & $479,146(48.7)$ & $235,692(48.3)$ \\
\hline \multicolumn{3}{|l|}{ Ethnicity } \\
\hline Danish & $882,056(89.6)$ & $438,536(89.9)$ \\
\hline Immigrant & $90,000(9.1)$ & $43,266(8.9)$ \\
\hline Descendants & $12,093(1.2)$ & $6137(1.3)$ \\
\hline \multicolumn{3}{|l|}{ Clinical characteristics } \\
\hline \multicolumn{3}{|l|}{ Comorbidity-Charlson Index } \\
\hline 0 & $806,330(81.9)$ & $396,184(81.2)$ \\
\hline 1 & $79,086(8.0)$ & $43,998(9.0)$ \\
\hline$>1$ & $98,733(10.0)$ & $47,757(9.8)$ \\
\hline \multicolumn{3}{|l|}{ Chronic condition ${ }^{\mathrm{a}}$} \\
\hline Yes & $824,315(83.8)$ & $409,481(83.9)$ \\
\hline No & $159,834(16.2)$ & $78,458(16.1)$ \\
\hline \multicolumn{3}{|l|}{ Number of consultations previous year } \\
\hline 0 & $116,831(11.9)$ & $57,508(11.8)$ \\
\hline $1-4$ & $488,284(49.6)$ & $244,483(50.1)$ \\
\hline$>4$ & $379,034(38.5)$ & $185,948(38.1)$ \\
\hline \multicolumn{3}{|l|}{ Number of antibiotic treatments previous year } \\
\hline 0 & $737,095(74.9)$ & $357,337(73.2)$ \\
\hline 1 & $179,624(18.3)$ & $93,444(19.2)$ \\
\hline$>1$ & $67,430(6.9)$ & $37,158(7.6)$ \\
\hline \multicolumn{3}{|l|}{ Number of CRP tests previous year } \\
\hline 0 & $702,522(71.4)$ & $338,392(69.4)$ \\
\hline 1 & $185,748(18.9)$ & $96,543(19.8)$ \\
\hline $2-$ & $95,879(9.7)$ & $53,004(10.9)$ \\
\hline
\end{tabular}


Table 1 (continued)

\begin{tabular}{|c|c|c|}
\hline & $\begin{array}{l}\text { The four types of antibiotics } \\
\text { recommended for RTIs }\end{array}$ & $\begin{array}{l}\text { The four types of antibiotics } \\
\text { recommended for RTIs with RTI as } \\
\text { stated indication }\end{array}$ \\
\hline \multicolumn{3}{|l|}{ Prescribing indication } \\
\hline Respiratory tract & 487,939 (49.6) & $487,939(100.0)$ \\
\hline Skin & $155,910(15.8)$ & - \\
\hline Other & $42,296(4.3)$ & - \\
\hline Infection & $170,882(17.4)$ & - \\
\hline Missing & $127,122(12.9)$ & - \\
\hline \multicolumn{3}{|l|}{ Season } \\
\hline October-March & $562,635(57.2)$ & $308,743(63.3)$ \\
\hline April-September & $421,514(42.8)$ & $179,196(36.7)$ \\
\hline
\end{tabular}

About missing data: Less than $1 \%$ were missing for gender, cohabitation, and working status. Around $2 \%$ missed information about education. Replaced values are presented in this table.

${ }^{a}$ Defined by patient being followed in practice with at least one chronic condition in the previous year

than males (OR 1.05 (95CI 1.04-1.06). Patients aged 75 years and above had lower odds for having a CRP test performed in relation to an antibiotic prescription (OR 0.82 (95CI 0.79-0.86)) compared to the youngest age group (18-44years). A Charlson Index above 1 was associated with lower odds for CRP testing (OR 0.93 (95CI 0.91-0.95)), compared to Charlson Index 0. Contrary, being followed in general practice for one or more chronic condition showed higher odds for having a CRP test performed in relation to an antibiotic prescription, OR (1.22 (95CI 1.18-1.26). Having an education of less than 10 years, living alone, being out of workforce or at disability pension or being immigrant or descendent from immigrants were all factors associated with lower odds of having a CRP test performed in relation to an antibiotic prescription. The analyses also showed lower odds for CRP testing for patients with more than one antibiotic prescription in the previous year (OR 0.75 (95CI 0.73-0.77), but the opposite if the patient had CRP tests performed in the previous year (OR 1.78 (95CI 1.73-1.84)). Finally, seasonal differences were observed with OR 0.71 (95CI 0.70-0.72) for CRP testing in relation to prescriptions during April to September.

When restricting analyses to prescriptions with a stated RTI (model 2), we found similar trends regarding the variables as for model 1 with a few exceptions. Regarding gender, the model 2 showed no differences between males and females, and for comorbidity a Charlson Index of 1 or above was associated with lower odds of having a CRP test performed in relation to antibiotic prescription.

Results of the univariable models and the sensitivity analysis for prescriptions with a possible RTI indication (comprising prescriptions with RTI, 'against infection' or missing indication) are presented in Additional file 2:
Additional models. The sensitivity analysis showed no major differences from model 1 .

\section{Discussion \\ Main findings}

This nationwide population-based study included 984,149 individuals who had received an antibiotic prescription recommended as first line treatment for RTIs during the 2-year study period. A total of $49.6 \%$ of the prescriptions had RTI stated as the indication. Differences in the use of CRP tests, when prescribing antibiotics, was identified both in relation to patient and clinical characteristics.

Both models showed that the odds of having a CRP test performed when prescribed antibiotics for an RTI was lower for the elderly (75 years and above), and for patients with comorbidity indicated by the Charlson Comorbidity Index $>1$. One of the reasons for this finding might be that clinical and medical history and the risk of complications in this age group carry more weight. Hence, GPs may not find CRP testing necessary when deciding to prescribe antibiotics for patients who are more vulnerable due to age and/or comorbidity. Furthermore, a proportion of these patients may be too old or frail to be able to attend general practice and will need home visits with no access to POC tests.

On the other hand, these groups are also more vulnerable to side-effects of antibiotics, meaning that diagnostic certainty should be prioritised. Being followed in general practice for one or more chronic condition was associated with higher odds of having a CRP test performed in relation to an antibiotic prescription for an RTI. In contrast, we find lower odds of CRP testing with higher comorbidity score, indicating that these two 
Table 2 Factors associated with the use of a CRP test in relation to antibiotic prescribing

\begin{tabular}{|c|c|c|c|c|}
\hline & \multicolumn{2}{|l|}{ Model 1} & \multicolumn{2}{|l|}{ Model 2} \\
\hline & $\begin{array}{l}\text { Number (\%) prescription } \\
\text { with CRP test }\end{array}$ & $\begin{array}{l}\text { Multivariable model for the } \\
\text { four types of antibiotics } \\
\text { recommended for RTls }\end{array}$ & $\begin{array}{l}\text { Number (\%) } \\
\text { prescription with } \\
\text { CRP test }\end{array}$ & $\begin{array}{l}\text { Multivariable model for the } \\
\text { four types of antibiotics } \\
\text { recommended for RTls with RT } \\
\text { as stated indication }\end{array}$ \\
\hline & $N=984,149$ & & $N=487,939$ & \\
\hline Patient characteristics & n (\%) & OR $(95 \% \mathrm{Cl})$ & n (\%) & OR $(95 \% \mathrm{Cl})$ \\
\hline Overall & $335,755(34.1)$ & & $220,733(45.2)$ & \\
\hline Male & $142,507(33.3)$ & 1 & $91,759(45.2)$ & 1 \\
\hline Female & $193,248(34.7)$ & $1.05(1.04-1.06)$ & $128,974(45.3)$ & $1.00(0.98-1.01)$ \\
\hline $18-44$ & $125,436(33.2)$ & 1 & $87,038(42.6)$ & 1 \\
\hline $45-64$ & $108,825(34.6)$ & $1.02(1.00-1.03)$ & $69,245(47.7)$ & $1.19(1.17-1.22)$ \\
\hline $65-74$ & $58,595(37.3)$ & $1.05(1.01-1.08)$ & $37,339(51.1)$ & $1.30(1.24-1.35)$ \\
\hline $75+$ & $42,899(31.7)$ & $0.82(0.79-0.86)$ & $27,111(41.5)$ & $0.91(0.86-0.96)$ \\
\hline Education $<10$ years & $67,899(33.1)$ & 1 & $44,292(43.3)$ & 1 \\
\hline Education 10-15years & $195,632(34.4)$ & $1.05(1.03-1.07)$ & $128,464(45.6)$ & $1.10(1.08-1.12)$ \\
\hline Education $>15$ years & $72,224(34.4)$ & $1.04(1.02-1.07)$ & $47,977(46.1)$ & $1.13(1.10-1.17)$ \\
\hline Working & $185,237(34.6)$ & 1 & $124,386(45.2)$ & 1 \\
\hline Pension & $100,956(34.7)$ & $1.00(0.98-1.03)$ & $64,294(46.6)$ & $1.01(0.97-1.05)$ \\
\hline Out of workforce or disability pension & $49,562(31.3)$ & $0.84(0.83-0.85)$ & $32,053(43.0)$ & $0.90(0.88-0.92)$ \\
\hline Single & $165,734(32.8)$ & 1 & $109,632(43.5)$ & 1 \\
\hline Married/Partner & $170,021(35.5)$ & $1.08(1.07-1.10)$ & $111,101(47.1)$ & $1.07(1.05-1.09)$ \\
\hline Danish & $303,038(34.4)$ & 1 & $199,482(45.5)$ & 1 \\
\hline Immigrant & $28,969(32.2)$ & $0.91(0.88-0.95)$ & $18,763(43.4)$ & $0.92(0.89-0.96)$ \\
\hline Descendant of immigrants & $3748(31.0)$ & $0.90(0.84-0.96)$ & $2488(40.5)$ & $0.91(0.84-0.98)$ \\
\hline \multicolumn{5}{|l|}{ Clinical characteristics } \\
\hline Charlson 0 & $274,552(34.0)$ & 1 & $180,384(45.5)$ & 1 \\
\hline Charlson 1 & $28,911(36.6)$ & $1.07(1.05-1.09)$ & $19,668(44.7)$ & $0.92(0.90-0.95)$ \\
\hline Charlson >1 & $32,292(32.7)$ & $0.93(0.91-0.95)$ & $20,681(43.3)$ & $0.87(0.84-0.90)$ \\
\hline No chronic conditions & $274,124(33.3)$ & 1 & $180,549(44.1)$ & 1 \\
\hline Chronic conditions $^{\mathrm{a}}$ & $61,631(38.6)$ & $1.22(1.18-1.26)$ & $40,184(51.2)$ & $1.24(1.19-1.29)$ \\
\hline 0 contacts previous year & $36,709(31.4)$ & 1 & $24,175(42.0)$ & 1 \\
\hline $1-4$ contacts previous year & $162,103(33.2)$ & $0.99(0.98-1.01)$ & $107,685(44.0)$ & $1.03(1.01-1.05)$ \\
\hline$>4$ contacts previous year & $136,943(36.1)$ & $1.03(1.00-1.05)$ & $88,873(47.8)$ & $1.13(1.10-1.17)$ \\
\hline 0 antibiotic treatments previous year & $253,058(34.3)$ & 1 & $165,331(46.3)$ & 1 \\
\hline 1 antibiotic treatment previous year & $61,385(34.2)$ & $0.91(0.90-0.93)$ & $40,834(43.7)$ & $0.83(0.82-0.85)$ \\
\hline$>1$ antibiotic treatment previous year & $21,312(31.6)$ & $0.75(0.73-0.77)$ & $14,568(39.2)$ & $0.64(0.62-0.66)$ \\
\hline 0 CRP previous year & $222,657(31.7)$ & 1 & $146,070(43.2)$ & 1 \\
\hline 1 CRP previous year & $70,752(38.1)$ & $1.33(1.30-1.36)$ & $46,585(48.3)$ & $1.23(1.20-1.27)$ \\
\hline$>1$ CRP previous year & $42,346(44.2)$ & $1.78(1.73-1.84)$ & $28,078(53.0)$ & $1.58(1.52-1.64)$ \\
\hline October-March & $210,163(37.4)$ & 1 & $141,915(46.0)$ & 1 \\
\hline April-September & $125,592(29.8)$ & $0.71(0.70-0.72)$ & $78,818(44.0)$ & $0.93(0.92-0.95)$ \\
\hline
\end{tabular}

a Defined by patient being followed in practice with at least one chronic condition in the previous year

measures might assess different aspects. Patients with more than four consultations in practice in the previous year had also higher odds for a CRP test, which may be explained by the fact that these patients are wellknown in practice and are more inclined to visit general practice for a test, and perhaps more related to the GP factor than patient factors.

CRP tests are also less used for individuals out of workforce or on disability pension, living alone, immigrants and descendants of immigrants, although the odds are 
only slightly lower compared to the reference groups. These findings suggest that some groups of patients might be treated differently with no evident differences in terms of risk of complications.

Having more than one CRP test performed in the previous year was a relative strong predictor of having a CRP test performed in relation to an antibiotic prescription, indicating that there is a group of patients, where CRP tests are more often used. Antibiotic treatment in the previous year reduced the chances of having a CRP test performed. This could be well-reasoned, but it could also reflect a tendency of repeating previous treatment without awareness about a potentially new situation. This could indicate that this is an area where CRP tests are not used to the optimal extent.

\section{Strengths and limitations of the study}

This study is based on nationwide registers, recognised for their high validity and ability to cover the entire Danish population, hereby providing a large data material.

However, some limitations must be considered when interpreting the results. The study used the Danish National Prescription Registry which gave us access to redeemed prescriptions. Prescriptions issued, but not redeemed, were not accessible. However, a previous Danish study have found that primary non-adherence for antibiotics is only $6.5 \%$ [26].

Another Danish study found that $32 \%$ of antibiotic prescriptions had a missing indication [19]. The indications used in this study are the ones stated by the GPs on the prescriptions and only $13 \%$ were missing. We attempted to account for this by estimating two models, one with all prescriptions and one with the subgroup of prescriptions with RTI as stated indication. The multivariable models were adjusted for all covariables, since these variables were selected based on hypothesis of influencing the main outcome. We did not take time trends into account, since the study period only covered two years, and as a recent study found that frequency of use of CRP tests did not change over the study period [17].

The database was restricted to patients who redeemed an antibiotic prescription. Hence, we were not able to assess patients for whom the GP chose to perform a CRP test but did not prescribe antibiotics, nor did we have access to the results of the tests. For future studies to further understand the diagnostic process, it could be relevant to study the way GPs use CRP tests also for patients who are not prescribed antibiotics and how the results of the CRP tests are used in the decision-making process. In this study it was not possible to distinguish OOHS from daytime in general practice. Different diagnostic approaches must be expected in general practice and in
OOHS, where the physician does not know the patient and has access to fewer diagnostic tools.

The study uses temporal links between CRP tests and antibiotic prescriptions. Data do not confirm whether it is the same GP who performed the test and issued the prescription. In addition, we allowed a timespan of up to 7 days between CRP test and prescription. This approach was necessary since the use of CRP tests are reported on a weekly basis. However, we consider this timespan clinically appropriate and would not expect it to constitute a large limitation to the study.

\section{Findings in relation to existing knowledge}

Antibiotic prescribing can be influenced by many factors such as patients' medical history; comorbidity; clinical examination; and the result of a CRP test $[16,18,27]$. We found differences in the use of CRP tests among different groups of patients. Odds for using CRP tests were lower for the elderly and patients with comorbidities (defined by Charlson Score above 1). Previous studies have shown that initial clinical judgement carry a high diagnostic value $[28,29]$. A recent Danish study found that the CRP threshold for prescribing antibiotics was lowered for patients with higher age and poor general appearance, indicating that CRP plays a minor role compared with these patient groups than with others [30].

Perhaps the clinical judgement plays a larger role with this group of patients, including assessment of probability of benefits of antibiotic use and potential risk of complications to the illness. However, the odds of having a CRP test performed when prescribed antibiotics for an RTI are also lower when the patient is out of workforce or on disability pension, living alone, an immigrant or descendant of immigrants. This correlates with previous studies from other areas showing that there is a social inequality in diagnosing in health care [31, 32]. The results of the present study indicate that GPs are prescribing antibiotics for elderly and socially marginalised using the CRP test as a diagnostic aid to a lesser extent. This could constitute a risk of irrational use of antibiotics including risk of side-effects and selection for resistant bacteria. On the other hand, the differences could also be interpreted as reflecting individualised patient care, thus possibly increasing quality of treatment.

We found that having a CRP performed in the previous year was associated with increased odds of having a CRP test in relation to an antibiotic prescription. This finding is in line with another study, which found that there are differences in the use of diagnostic tests between practices in the range of use of diagnostic tests [33]. Odds ratios cannot necessarily be compared across variables. However, the sizes of the ORs for previous CRP tests and previous antibiotic treatments are quite high, indicating 
that these somewhat more GP-related factors play a large role. This could be further explored in future studies.

\section{Implications}

This study discovered differences in the use of CRP tests among different patient groups. Socially deprived patients had lower odds of having a CRP test performed in relation to an antibiotic prescription for an RTI. Further studies should attempt to get a deeper knowledge of the rationale behind differences in the use of CRP tests among patients, with a special focus on socioeconomic inequality. The influence of GP factors on the decision to use a CRP test was not assessed in this study, however this angle could also be an important topic for future studies.

Furthermore, the study findings might indicate that the existing evidence on when to use the CRP test could be implemented more explicitly in the clinical recommendations for treatment of RTIs. In a broader perspective, it must be expected that a wider selection of POC tests will be available in the future.

\section{Conclusion}

Differences were observed in the use of CRP tests among subgroups of patients treated with antibiotics for an RTI, indicating that sociodemographic factors and comorbidity influence the decision to use a CRP test in relation to antibiotic prescriptions in general practice.

Potentially, this means that the use of CRP tests could be optimised to increase diagnostic certainty and further promote rational prescribing of antibiotics. The rationale behind the observed differences could be further explored in future qualitative studies.

\section{Abbreviations}

CRP: C-reactive protein; 95Cl: 95\% confidence interval; GP: General practitioner; OR: Odds ratio; RTI: Respiratory tract infection.

\section{Supplementary Information}

The online version contains supplementary material available at https://doi. org/10.1186/s12875-021-01614-6.

Additional file 1: List of indication codes and categorisation for prescriptions.

Additional file 2: Additional models.

\section{Acknowledgements}

We would like to thank Maria Storsveen for data management.

\section{Authors' contributions}

RVS, MPH, USJ, LBP, RMA, SW and DEJ took part in developing the project idea. RVS, SW and DEJ developed the analysis plan. Statistical analysis was performed by RVS. RVS drafted the manuscript. RVS, MPH, USJ, LBP, RMA, SW and DEJ read and approved the final manuscript.
Authors' information

Not applicable.

\section{Funding}

The Danish Ministry of Health (journal number 1608957) funded salary for project staff and establishment and maintenance of registers. The Region of Southern Denmark (journal number 15/51294), Knud and Edith Eriksen's Memorial Foundation and The Foundation for General Practice (journal number R38-A947) funded salary for project staff.

\section{Availability of data and materials}

The data that support the findings of this study are available from Statistics Denmark, but restrictions apply to the availability of these data, which were used under license for the current study, and so are not publicly available. Data are however available from the authors upon reasonable request and with permission of Statistics Denmark.

\section{Declarations}

Ethics approval and consent to participate

Complying with European data protection rules, the University of Southern Denmark registered the data processing activities regarding this project (registration number 10.053). Data were obtained from Danish national registries, and the study was approved by the Danish National Health Data Board (FSEID00004071) and the Danish Patient Safety Authority (3-3013-2095/1). According to Danish law a strictly register-based study needs no approval from The Regional Committees on Health Research Ethics for Southern Denmark, neither from the participants. All methods were performed in accordance with the relevant guidelines and regulations (Declaration of Helsinki).

\section{Consent for publication}

Not applicable.

\section{Competing interests}

The authors declare no competing interests.

\section{Author details}

${ }^{1}$ Research Unit of General Practice, Institute of Public Health, University of Southern Denmark, JB Winsløws Vej 9A, 5000 Odense C, Denmark. ${ }^{2}$ Center for General Practice at Aalborg University, Aalborg, Denmark. ${ }^{3}$ Department of Clinical Microbiology, Odense University Hospital, Odense, Denmark. ${ }^{4}$ Danish Centre for Health Economics, Institute of Public Health, University of Southern Denmark, Odense, Denmark. ${ }^{5}$ Research Unit for General Practice, University of Copenhagen, Copenhagen, Denmark.

Received: 30 January 2021 Accepted: 14 December 2021

Published online: 22 January 2022

\section{References}

1. Harnden A, Perera R, Brueggemann AB, Mayon-White R, Crook DW, Thomson A, et al. Respiratory infections for which general practitioners consider prescribing an antibiotic: a prospective study. Arch Dis Child. 2007:92(7):594-7.

2. Gonzales R, Steiner JF, Sande MA. Antibiotic prescribing for adults with colds, upper respiratory tract infections, and bronchitis by ambulatory care physicians. JAMA. 1997;278(11):901-4.

3. Renati $S$, Linder JA. Necessity of office visits for acute respiratory infections in primary care. Fam Pract. 2016;33(3):312-7.

4. Straand J, Rokstad KS, Sandvik H. Prescribing systemic antibiotics in general practice. A report from the more \& Romsdal prescription study. Scand J Prim Health Care. 1998;16(2):121-7.

5. Kenealy T, Arroll B. Antibiotics for the common cold and acute purulent rhinitis. Cochr Database Syst Rev. 2013;2013(6):Cd000247.

6. Costelloe C, Metcalfe C, Lovering A, Mant D, Hay AD. Effect of antibiotic prescribing in primary care on antimicrobial resistance in individual patients: systematic review and meta-analysis. BMJ. 2010;340:c2096.

7. World Health Organization. An introduction to the international classification of primary care version 2World Organization of family doctors; 2012. 
8. World Health Organization. Global action plan on antimicrobial resistance. Geneva: World Health Organization; 2015. p. 2015.

9. Bjerrum LG-H, B. Hansen MP, et al. Luftvejsinfektioner - diagnose og behandling 2014; 2014.

10. Fischer T, Fischer S, Kochen MM, Hummers-Pradier E. Influence of patient symptoms and physical findings on general practitioners' treatment of respiratory tract infections: a direct observation study. BMC Fam Pract. 2005;6(1):6.

11. Hopstaken RM, Butler CC, Muris JW, Knottnerus JA, Kester AD, Rinkens PE, et al. Do clinical findings in lower respiratory tract infection help general practitioners prescribe antibiotics appropriately? An observational cohort study in general practice. Fam Pract. 2006;23(2):180-7.

12. Brookes-Howell L, Hood K, Cooper L, Coenen S, Little P, Verheij T, et al. Clinical influences on antibiotic prescribing decisions for lower respiratory tract infection: a nine country qualitative study of variation in care. BMJ Open. 2012;2(3). https://doi.org/10.1136/bmjopen-2011-000795.

13. Dempsey PP, Businger AC, Whaley LE, Gagne JJ, Linder JA. Primary care clinicians' perceptions about antibiotic prescribing for acute bronchitis: a qualitative study. BMC Fam Pract. 2014;15:194.

14. Lindström J, Nordeman L, Hagström B. What a difference a CRP makes. A prospective observational study on how point-of-care C-reactive protein testing influences antibiotic prescription for respiratory tract infections in Swedish primary health care. Scand J Prim Health Care. 2015;33(4):275-82.

15. Pedersen KM, Andersen JS, Sondergaard J. General practice and primary health care in Denmark. J Am Board Fam Med. 2012;25(Suppl 1):S34-8.

16. Sydenham RV, Jarbøl DE, Hansen MP, Justesen US, Watson V, Pedersen LB. Prescribing antibiotics: factors driving decision-making in general practice. A discrete choice experiment; 2020.

17. Sydenham RV, Justesen US, Hansen MP, Pedersen LB, Aabenhus RM, Wehberg S, et al. Prescribing antibiotics: the use of diagnostic tests in general practice. A register-based study. 2020.

18. O'Connor R, O'Doherty J, O'Regan A, Dunne C. Antibiotic use for acute respiratory tract infections (ARTI) in primary care; what factors affect prescribing and why is it important? A narrative review. Ir J Med Sci. 2018;187(4):969-86.

19. Aabenhus R, Hansen MP, Siersma V, Bjerrum L. Clinical indications for antibiotic use in Danish general practice: results from a nationwide electronic prescription database. Scand J Prim Health Care. 2017;35(2):162-9.

20. Tonkin-Crine SK, Tan PS, van Hecke O, Wang K, Roberts NW, McCullough $A$, et al. Clinician-targeted interventions to influence antibiotic prescribing behaviour for acute respiratory infections in primary care: an overview of systematic reviews. Cochr Database Syst Rev. 2017;9(9):Cd012252.

21. Kavanagh KE, O'Shea E, Halloran R, Cantillon P, Murphy AW. A pilot study of the use of near-patient $\mathrm{C}$-reactive protein testing in the treatment of adult respiratory tract infections in one Irish general practice. BMC Fam Pract. 2011;12:93.

22. Martínez-González NA, Keizer E, Plate A, Coenen S, Valeri F, Verbakel JYJ, et al. Point-of-care $\mathrm{C}$-reactive protein testing to reduce antibiotic prescribing for respiratory tract infections in primary care: systematic review and meta-analysis of randomised controlled trials. Antibiotics (Basel). 2020;9(9). https://doi.org/10.3390/antibiotics9090610.

23. National Institute for Health and Care Excellence. QuikRead go for C-reactive protein testing in primary care. Medtech innovation briefing [MIB78] www.nice.org.uk2016 [Available from: https://www.nice.org.uk/ advice/mib78/chapter/The-technology\#population-setting-and-inten ded-user.

24. Quan H, Li B, Couris CM, Fushimi K, Graham P, Hider P, et al. Updating and validating the Charlson comorbidity index and score for risk adjustment in hospital discharge abstracts using data from 6 countries. Am J Epidemiol. 2011;173(6):676-82.

25. StataCorp. Stata statistical software: release 16. College Station: StataCorp LLC; 2019

26. Pottegård A, Christensen R, Houji A, Christiansen CB, Paulsen MS, Thomsen $\mathrm{J} L$, et al. Primary non-adherence in general practice: a Danish register study. Eur J Clin Pharmacol. 2014:70(6):757-63.

27. Jakobsen KA, Melbye H, Kelly MJ, Ceynowa C, Molstad S, Hood K, et al. Influence of CRP testing and clinical findings on antibiotic prescribing in adults presenting with acute cough in primary care. Scand J Prim Health Care. 2010;28(4):229-36.
28. Dale AP, Marchello C, Ebell MH. Clinical gestalt to diagnose pneumonia, sinusitis, and pharyngitis: a meta-analysis. Brit J Gen Practice. 2019:69(684):e444-e53.

29. Ebell MH, Chupp H, Cai X, Bentivegna M, Kearney M. Accuracy of signs and symptoms for the diagnosis of community-acquired pneumonia: a meta-analysis. Acad Emerg Med. 2020;27(7):541-53.

30. Lykkegaard J, Olsen JK, Sydenham RV, Hansen MP. C-reactive protein cutoffs used for acute respiratory infections in Danish general practice. BJGP Open. 2021;5(1). https://doi.org/10.3399/bjgpopen20X101136.

31. Hansen RP, Olesen F, Sørensen HT, Sokolowski I, Søndergaard J. Socioeconomic patient characteristics predict delay in cancer diagnosis: a Danish cohort study. BMC Health Serv Res. 2008;8(1):49.

32. Institute of Medicine Committee on U, Eliminating R, Ethnic Disparities in Health C. In: Smedley BD, Stith AY, Nelson AR, editors. Unequal treatment: confronting racial and ethnic disparities in health care. Washington (DC): National Academies Press (US)Copyright 2002 by the National Academy of Sciences. All rights reserved; 2003.

33. Haldrup S, Thomsen RW, Bro F, Skov R, Bjerrum L, Søgaard M. Microbiological point of care testing before antibiotic prescribing in primary care: considerable variations between practices. BMC Fam Pract. 2017;18(1):9.

\section{Publisher's Note}

Springer Nature remains neutral with regard to jurisdictional claims in published maps and institutional affiliations.

Ready to submit your research? Choose BMC and benefit from:

- fast, convenient online submission

- thorough peer review by experienced researchers in your field

- rapid publication on acceptance

- support for research data, including large and complex data types

- gold Open Access which fosters wider collaboration and increased citations

- maximum visibility for your research: over $100 \mathrm{M}$ website views per year

At BMC, research is always in progress.

Learn more biomedcentral.com/submissions 